\title{
Extramacular dome-shaped elevation: a novel finding in a case of high myopia
}

\author{
Vineet Mutha, Atul Kumar, Rohan Chawla, Raghav Dinesh Ravani
}

Department of Ophthalmology, Dr. Rajendra Prasad Centre for Ophthalmic Sciences, AllMS, New Delhi, India

\section{Correspondence to Dr Vineet Mutha,} neetvinit@gmail.com

Accepted 7 July 2017
CrossMark

To cite: Mutha $V_{\text {, Kumar } A}$ Chawla R, et al. BMJ Case Rep Published Online First: [please include Day Month Year]. doi:10.1136/bcr-2017220861

\section{DESCRIPTION}

Dome-shaped macula (DSM) is an elevation at the macula seen in about 5\%-10\% cases of high myopia, usually within a posterior staphyloma, caused by localised inward scleral and choroidal convexity. ${ }^{1}$ It may lead to visual deterioration when associated with serous foveal detachment (44\% cases). ${ }^{2}{ }^{3}$ Herein, we describe a similar but 'Extramacular dome-shaped elevation (EDSE)' associated with a large retinal hole.

A 23-year-old myopic female patient was referred to our clinic for pre refractive surgery fundus screening. She had a history of diminution of vision in the left eye more than the right eye since childhood and was using myopic glasses for the same. Best-corrected visual acuity on Snellen chart was $20 / 20$ in the right eye and 20/200 in the left eye. Lower acuity in the left eye was attributed to anisometropic amblyopia as her refractive error was $-6.75 \mathrm{D}$ sphere OD and $-17.25 \mathrm{D}$ sphere OS with an axial length of $26.62 \mathrm{~mm}$ OD and $32.85 \mathrm{~mm}$ OS on IOL Master (Carl Zeiss, Jena, Germany). Fundus examination on indirect ophthalmoscopy revealed a myopic fundus with tessellations and tilted disc, Curtin type I posterior staphyloma, myelinated nerve fibres, a large hole superiorly above the retinal vascular arcades of about three disc diameter size along with a Weiss ring suggestive of a complete posterior vitreous detachment in the left eye (figure 1A). Fundus examination was per se normal without any myopic degenerative changes in the right eye.

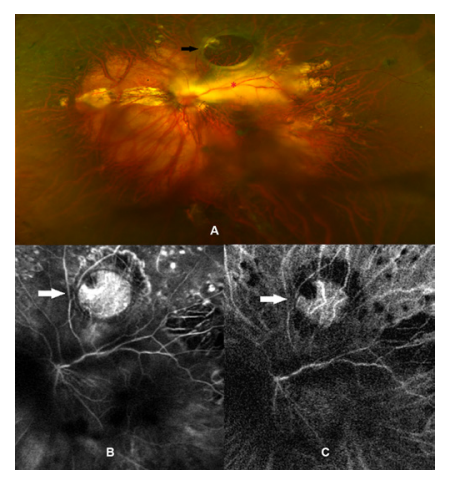

Figure 1 Optos widefield fundus photograph (A) of the patient's left eye showing tessellated fundus, tilted disc, superotemporal myelinated nerve fibres (red asterisk) and a large retinal hole above the superior arcade (black arrow). Fluorescein angiography (B) and indocyanine green angiography figures $(C)$ are suggestive of window defect through the retinal hole (white arrow).

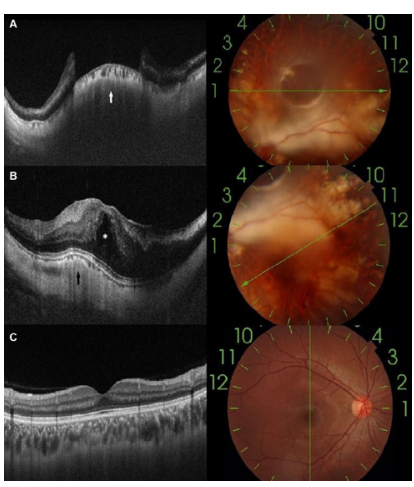

Figure 2 Swept source optical coherence tomography figures: $12 \mathrm{~mm}$ scan via the retinal hole in the left eye $(A)$ indicating extramacular dome-shaped elevation with an overlying retinal hole (minimum diameter $=3341 \mu$ ) with a choroidal thickness of $114 \mu$ and an inward convex bulge of sclera (white arrow). A $12 \mathrm{~mm}$ scan via the fovea in the left eye (B) shows a dome-shaped macula (black arrow), altered foveal contour and an increased retinal thickness of $539 \mu$ with cystoid changes (white asterisk). The $12 \mathrm{~mm}$ scan via the fovea in the right eye (C) showing normal foveal contour with a thickness of $211 \mu$ (all measurements were done manually).

Swept source optical coherence tomography (SSOCT) (Triton - Topcon, Tokyo, Japan) of the left eye: radial scans $(12 \mathrm{~mm})$ passing via the fovea showed a dome-shaped macula with increased foveal thickness $(539 \mu)$ and cystoid changes at the fovea with altered foveal contour. Radial scans $(12 \mathrm{~mm})$ passing via the retinal hole showed a minimum hole diameter of $3341 \mu$ and an underlying dome-shaped elevation with a choroidal thickness of $114 \mu$ and an inward scleral bend. SSOCT in the right eye revealed normal foveal contour and thickness of $211 \mu$ (figure 2). Fundus fluorescein angiography and indocyanine green angiography revealed a window defect in the area of macular hole (figure 1B,C). There was no definite leakage at the site of DSM despite cystoid changes on SSOCT.

Various theories proposed for DSM are sublesional scleral thickening, ${ }^{1}$ inward convex contour of the choroid and sclera ${ }^{12}$ and localised choroidal thickening. ${ }^{3}$ Inward convex contour of the sclera and choroid along with sublesional scleral thickening was present in our case at the site of DSM and EDSE, and thus it appears to contribute towards the formation of both DSM and EDSE, suggesting that they originate from a similar but unknown pathophysiology. To the best of our knowledge, an EDSE alone or along with a large retinal hole, as in our 
case, has not been described elsewhere and can be added to the vast clinical spectrum of high myopia.

\section{Learning points}

- Dome-shaped elevation can be found in extramacular location also, in high myopic eyes with posterior staphyloma.

- Both dome-shaped macula and extramacular dome-shaped elevation (EDSE) occur as a result of inward scleral bulge and can be diagnosed on optical coherence tomography.

- EDSE can be associated with a retinal hole.
Contributors VM: Corresponding and first author; AK: Case selection and imaging; RC: Case description and image analysis; RDR: Text editing and literature search.

Competing interests None declared.

Patient consent Obtained.

Provenance and peer review Not commissioned; externally peer reviewed.

(C) BMJ Publishing Group Ltd (unless otherwise stated in the text of the article) 2017. All rights reserved. No commercial use is permitted unless otherwise expressly granted.

\section{REFERENCES}

1. Mehdizadeh M, Nowroozzadeh MH. Dome-shaped macula in eyes with myopic posterior staphyloma. Am J Ophthalmol 2008;146:478.

2. Gaucher D, Erginay A, Lecleire-Collet A, et al. Dome-shaped macula in eyes with myopic posterior staphyloma. Am J Ophthalmol 2008;145:909-14.

3. Viola F, Dell'Arti L, Benatti E, et al. Choroidal findings in dome-shaped macula in highly myopic eyes: a longitudinal study. Am J Ophthalmol 2015;159:44-52.

Copyright 2017 BMJ Publishing Group. All rights reserved. For permission to reuse any of this content visit http://group.bmj.com/group/rights-licensing/permissions.

BMJ Case Report Fellows may re-use this article for personal use and teaching without any further permission.

Become a Fellow of BMJ Case Reports today and you can:

- Submit as many cases as you like

- Enjoy fast sympathetic peer review and rapid publication of accepted articles

- Access all the published articles

Re-use any of the published material for personal use and teaching without further permission

For information on Institutional Fellowships contact consortiasales@bmjgroup.com

Visit casereports.bmj.com for more articles like this and to become a Fellow 